\title{
PERFORMANCE AND OPERATING CHARACTERISTICS OF COMPACT SOLAR THERMAL AND GEOTHERMAL HYBRID HEAT PUMP SYSTEMS FOR A ZERO-ENERGY HOUSE
}

\author{
NAMCHOON BAEK ${ }^{1}$, WANG-JAE LEE ${ }^{1}$ \& UCHEUL SHIN ${ }^{2}$ \\ ${ }^{1}$ Solar Thermal Laboratory, Korea Institute of Energy Research, Republic of Korea \\ ${ }^{2}$ Department of Architectural Engineering, Daejeon University, Republic of Korea
}

\begin{abstract}
In this study, the operating characteristics and thermal performance of a geothermal heat pump for a compact solar thermal and geothermal hybrid heat pump system that had been developed through previous studies for a zero-energy residential house were experimentally analyzed. This hybrid system was installed in a passive three-story house with a heating area of $194 \mathrm{~m}^{2}$. The geothermal heat pump was used as backup for heating and cooling and the solar hot water system. Monitoring results showed that the daily heating COP of the geothermal heat pump was 3.7 to 4.6 and the cooling COP was 3.9 to 4.7, depending on the temperature of the heating medium supplied from the borehole heat exchanger to the heat pump and the temperature condition of the buffer storage tank. The operation pattern of the geothermal heat pump during the winter season showed continuous intermittent operations from the evening to early morning hours. One of the operation times was as short as about 10 minutes. Even during the summer, when the cooling load is high, the operation pattern of the heat pump showed intermittent operation characteristics similar to those of the winter season. The operation time of the heat pump was about 7 minutes. From such monitoring results, it is considered that the compact-type solar thermal and geothermal hybrid heat pump system needs to increase its buffer tank volume for heating and cooling or slightly reduce its heat pump capacity. If a variable output heat pump is used, the output of the heat pump can be adjusted to accommodate the instantaneous thermal load (not only the full load, but also the partial load), so that a solar thermal and geothermal hybrid system can be made more compact by eliminating the buffer storage tank for cooling and heating.

Keywords: ground source heat pump, solar/geothermal hybrid heat pump, zero-energy house, solar water heating system, experimental analysis.
\end{abstract}

\section{INTRODUCTION}

Renewable energy systems technology is just as important as the passive technology for zero-energy houses. Passive technology can significantly reduce the heating and cooling load of a house, but it cannot be self-reliant. New renewable energy technology must be introduced alongside passive technology to solve the residual heating and cooling load issue, which also applies to water heating loads, electrical energy loads, and cooking loads. Therefore, zeroenergy houses can only be achieved through the proper and adequate combination of passive and renewable energy technologies.

Renewable energy technologies, which are currently being applied to households, include PV systems, solar thermal systems, and geothermal heat pump (hereafter referred to as "GHP”) systems. Among them, the solar thermal and GHP systems are capable of supplying heat loads (heating, cooling, and hot water). Solar thermal systems have very little drive energy to generate heat (typically around $3 \%$ of the heat), but they are sensitive to weather conditions and require backup devices. In contrast, GHP systems require significant amounts of electrical energy to generate heat, but they can supply heat at any time regardless of weather conditions and do not require separate backup devices. In order to make up for the 
shortcomings of these two systems and to maximize their merits, there has been considerable amounts of studies on solar thermal and GHP hybrid heat supply systems.

This hybrid system was first applied in Korea to Zero-Energy Solar House I of the Korea Energy Technology Research Institute (KIER). This system requires a complex and large-area machine room. Therefore, there are limitations to the use of heating, cooling, and hot water facilities in the average households. Baek et al. [5], conducted a study on the optimization and compactness of the hybrid system for heating, cooling, and hot-water supplies to a zero-energy house. Due to the large volume requirements of the buffer and hot water tanks, there were limitations to the usage of factory-made products. In addition, there was difficulty in analyzing the characteristics of annual cooling and heating operations for these experimental houses as they did not have any residents.

Therefore, in this study, factory-made, hybrid compact systems were installed in low energy residences to analyze their thermal performances, COPs, and operating characteristics during the summer and winter seasons. The purpose of this study is to provide basic data for promoting the commercialization of hybrid systems in residential buildings.

Demonstration system overview

\subsection{The hybrid solar thermal and GHP system (“hybrid system”)}

Fig. 1 is a conceptual view of a hybrid system installed in a demonstration house. The system consists of a single vacuum tube solar collector, GHP, borehole, hot water storage tank, buffer tank for heating and cooling, control unit, and pump. An overview of the hybrid system is shown in Table 1 and Fig. 2. Here, the parts coloured in grey are compacted into a single product that can be factory-produced, and the system can be installed by simply connecting the pipes in the field. This device is a compact thermal energy supply device (CESD).

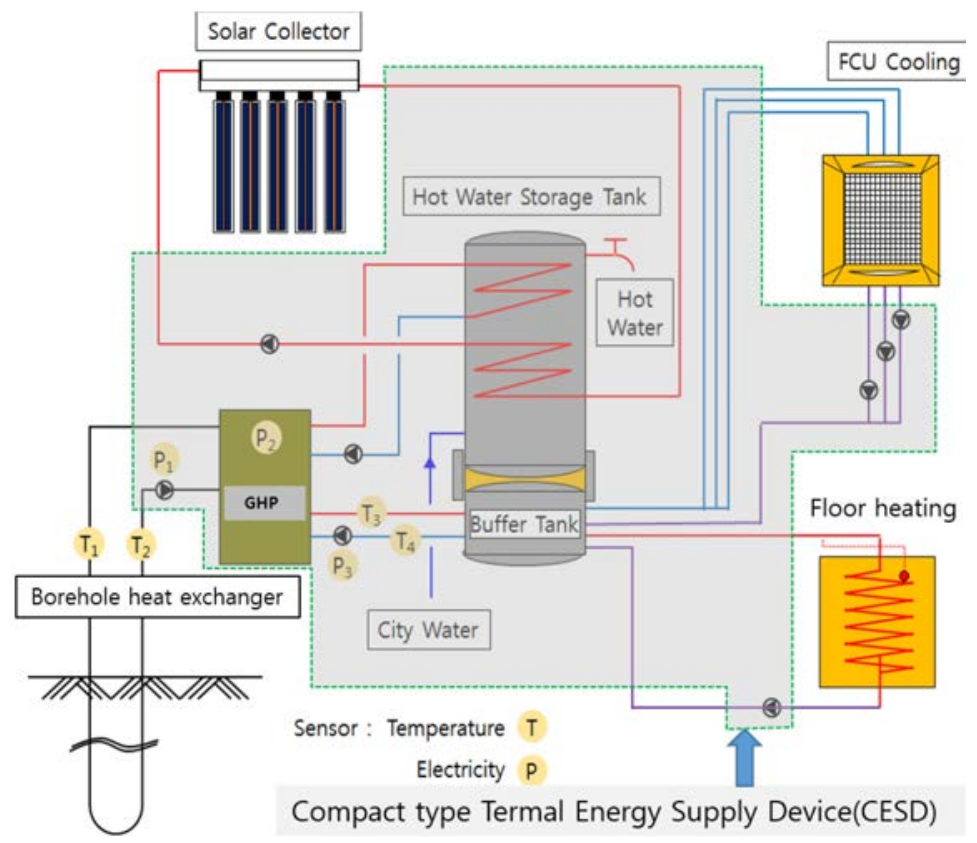

Figure 1: Schematics of the hybrid solar thermal/GHP system. 


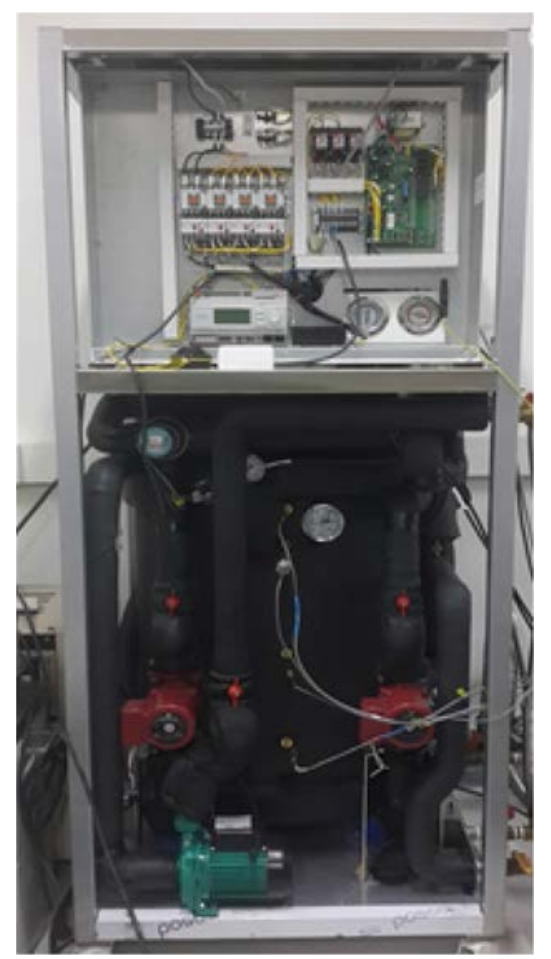

Figure 2: Hybrid compact system.

The solar collector heats the hot water storage tank through a heat exchanger installed at the bottom of the tank. The GHP is connected to the heating buffer tank and the upper end of the hot water storage tank, which is heated to sustain a constant temperature. The heat pump always operates in hot water priority mode. The buffer tank is used as a heat storage tank for cooling during the summer season, and this cooling is performed by six ceiling fan coil units that are installed in each room.

Table 1: Thermal energy system specifications.

\begin{tabular}{|c|c|c|c|}
\hline \multicolumn{2}{|l|}{ Items } & Specifications & Remark \\
\hline \multirow{2}{*}{ Solar collector } & Type & Evacuated tube & Single tube \\
\hline & Total area & $4 \mathrm{~m}^{2}$ & Aperture area \\
\hline $\begin{array}{l}\text { Ground source heat } \\
\text { pump (GHP) }\end{array}$ & Capacity & 3RT & Nominal capacity \\
\hline \multirow{2}{*}{ Borehole } & Number & 2 & \\
\hline & Depth & $120 \mathrm{~m}$ & \\
\hline \multirow{2}{*}{ Buffer tank } & Volume & $150 \mathrm{~L}$ & \\
\hline & Insulation & $100 \mathrm{~mm}$ & \\
\hline \multirow{2}{*}{$\begin{array}{l}\text { Circulation pump for } \\
\text { ground loop }\left(\mathrm{P}_{1}\right)\end{array}$} & Flowrate & 55.8LPM & \multirow{2}{*}{ Measured } \\
\hline & Power & $480 \mathrm{~W}$ & \\
\hline \multirow{2}{*}{$\begin{array}{l}\text { Circulation pump for } \\
\text { buffer } \operatorname{tank}\left(\mathrm{P}_{3}\right)\end{array}$} & Flowrate & 41.6LPM & \multirow{2}{*}{ Measured } \\
\hline & Power & $185 W$ & \\
\hline
\end{tabular}




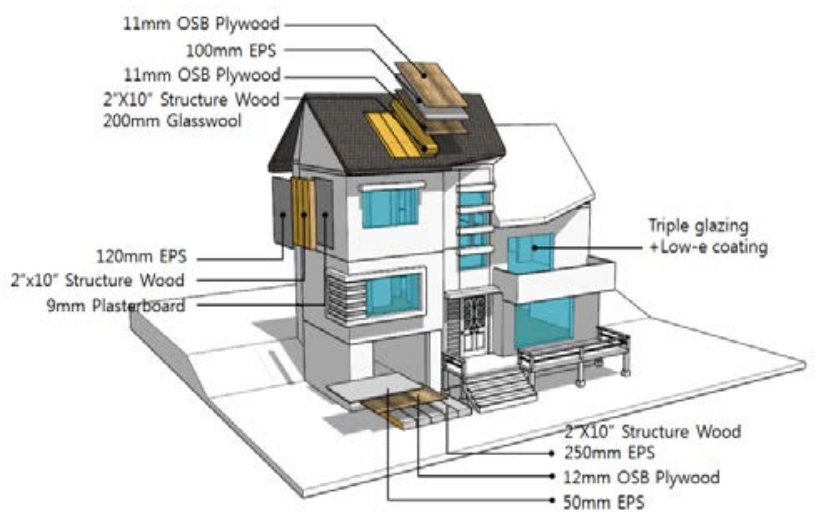

Figure 3: Building shape and exterior wall insulation.

Table 2: Building area and heat transmission efficiency by exterior walls.

\begin{tabular}{|l|l|l|}
\hline Items & $\begin{array}{l}\text { Building } \\
\text { floor area }\end{array}$ & 87 \\
\cline { 2 - 3 } Area $\left(\mathrm{m}^{2}\right)$ & $\begin{array}{l}\text { Gross floor } \\
\text { area }\end{array}$ & 194 \\
\cline { 2 - 3 } & Heating area & 194 \\
\hline \multirow{2}{*}{$\begin{array}{l}\text { Heat } \\
\text { Transmission } \\
\text { Co-efficiency } \\
\left(\mathrm{W} / \mathrm{m}^{2} \mathrm{~K}\right)\end{array}$} & Roof & 0.10 \\
\cline { 2 - 3 } & Wall & 0.13 \\
\cline { 2 - 3 } & Floor & 0.10 \\
\cline { 2 - 3 } & Window & 0.97 \\
\hline
\end{tabular}

\subsection{Overview of the zero-energy house}

The zero-energy house with a hybrid system is shown in Fig. 3. Table 2 shows the heat transfer coefficient of the outer wall of the building. This house was completed in July 2011. A single $4 \mathrm{~m}^{2}$ vacuum tube collector and $3 \mathrm{kWp}$ PV modules were installed on a southwardfacing roof with an inclination of 30 degrees.

\subsection{Monitoring system}

A web-based remote monitoring system was constructed to analyze the dynamic behaviour of the GHPs in the hybrid system. The measurement elements as shown in Fig. 1 are the first and second medium heat temperature of the GHP, circulating pump short-circuit signal, power consumption of the GHP, and the circulation pump. All data is measured and stored at 1-minute intervals.

\section{OPERATION AND PERFORMANCE ANALYSIS ON HYBRID GHP SYSTEM.}

The thermal performance of the GHPs operated for solar thermal system back-up and summer cooling was based on a one-year pilot study conducted from October 1, 2014 to September 
30, 2015. The COP representing the thermal performance of the GHP can be calculated as shown in eqn (1):

$$
\boldsymbol{C O P}=\frac{\text { Thermal energy production by heat pump }}{\text { Heat pump power consumption }+ \text { Circulation pump power consumption }}
$$

In order to examine the relationship between the CESDs and GHPs for the zero-energy residential unit, the operational characteristics, performance, and load follow-up of the GHPs were examined.

\subsection{Thermal performance of the GHP during the winter}

Performance evaluation and analysis were carried out for specific days (Jan. 1, 2014) in order to investigate the thermal performance of GHPs during the winter. Fig. 4 shows the indoor and outdoor temperatures on a specific day during the winter, with an average outdoor temperature of $-4.7^{\circ} \mathrm{C}$ and daily horizontal radiation of $9.5 \mathrm{MJ} / \mathrm{m}^{2}$. The indoor temperature of this zero-energy house is $23^{\circ} \mathrm{C}$, and it can be seen that the room temperature is kept almost constant (around $\pm 1^{\circ} \mathrm{C}$ ) as shown in the figure.

The instantaneous power of the GHP and the instant COP system are shown in Fig. 5. It can be seen that the ON-OFF operations of the heat pump frequently occur during the evening hours (from 16:00 to 02:00), during which significant heating loads occur, and during the morning hours, where there is considerable hot water loads. On the other hand, during the daytime, the heat pump did not work due to the inflow of solar radiation into the house even though the outside temperature GHP was about 10 minutes and had been operated about 20 times between 16:00 and 02:00. The total daily operation time was 271 minutes.

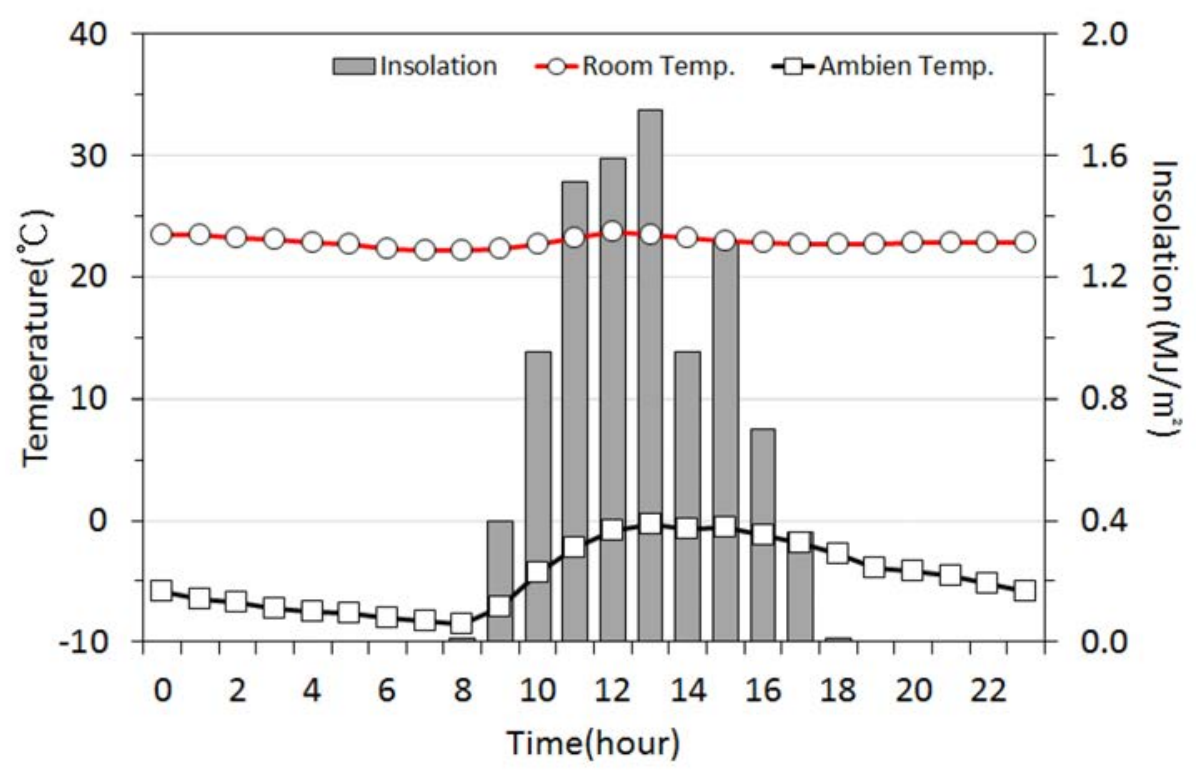

Figure 4: Indoor and ambient conditions (temperature and insolation). 
Some of the reasons why the GHP operates relatively frequently are as follows:

- $\quad$ Output of heat pump compared to load;

- Storage capacity of the buffer tank; and

- Gap between room temperature control and heat radiation rate $\left( \pm 1^{\circ} \mathrm{C}\right.$ in this case).

This can be seen from the monitoring results. Figs 5 and 6 show that the capacity of the heat pump is large while the volume of the buffer tank is small. That is, the heat pump is repeatedly turned ON while the duration of the operation is very short.

At present, the minimum capacity of residential GHPs in Korea is $3 \mathrm{~kW}$ (compressor power consumption). Recently, the application of passive technology (e.g. high insulation, high airtightness, high-performance windows) of housing has reduced the heating load significantly, so the necessity of smaller capacity GHPs is growing.

From the experimental results shown in Figs 5 and 6, it is assessed that the heat pump is operated repeatedly for a short period of time due to the large capacity of the heat pump and the small capacity of the buffer tank.

At present, the minimum capacity of residential GHP in Korea is 3RT. Recently, the application of passive technology in houses has resulted in a significant reduction in heating load and the need for a GHP with a lower capacity than 3RT - the current minimum capacity.

In order to operate the GHP more efficiently in this system, it is necessary to reduce the number of operation. For this purpose, it is desirable to increase the capacity of the buffer tank to extend the operational duration and reduce its number. The capacity of the buffer tank can be increased to do so, but the disadvantage is that the volume of the CESD and heat loss increase. Although there are no products certified as a GHP in Korea as of yet, it is considered to be more effective to use the output variable heat pump to resolve the above issues more effectively. In this case, a buffer tank for cooling and heating would not be necessary, and the CESD could be made more compact.

The instantaneous power required for the heat pump was $3.1 \mathrm{~kW}(\sigma=0.12)$, and the system COP was $4.2 \mathrm{~kW}(\sigma=0.42)$. In the previous study, it can be seen that the COP of the heat pump of the same capacity is considerably higher than that of 2.5-3.5. This is because the installation capacity of the underground heat exchanger is large, which can be attributed to the low heating water supply temperature and large capacity borehole heat exchanger, as shown in Figs 8 and 9 below.

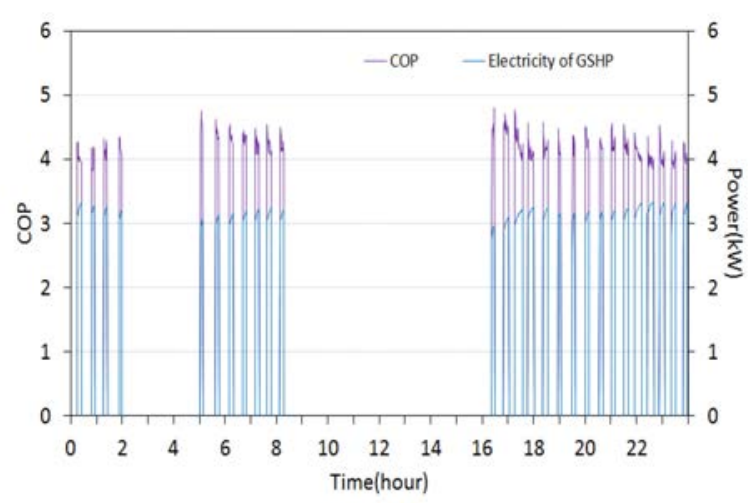

Figure 5: COP and electrical input power for GSHP. 


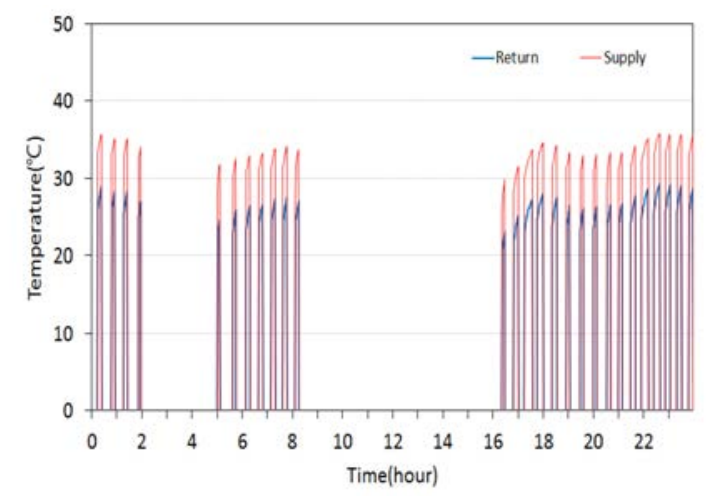

Figure 6: Hot water supply and return temperatures of the house.

Fig. 6 shows the inlet and outlet temperatures of the heating water supplied from the buffer tank to the load side. The average supply and return temperatures are $32.8^{\circ} \mathrm{C}$ and $25.9^{\circ} \mathrm{C}$, respectively, which is considerably lower than the range of $40^{\circ} \mathrm{C}$ to $60^{\circ} \mathrm{C}$ for conventional houses. This shows that the indoor temperature is maintained through the radiation of low-temperature heat in the passive house, which resulted in such high thermal performance of the GHP.

Since the output heat of the GHP is sufficiently high, the heating of the buffer tank by the heat pump is only performed when needed to reduce unnecessary heat loss in the buffer tank. The temperature of the supplied heating water increased over time, indicating that the temperature of the heat pump output was higher than that of the heat load.

\subsection{GHP performance during the summer}

Performance evaluation and analysis were conducted for a specific day (Apr. 25) to examine the cooling performance of the GHP. Fig. 7 shows the room and ambient temperatures and insolation. The highest ambient temperature was $35^{\circ} \mathrm{C}$ and the lowest temperature was $26^{\circ} \mathrm{C}$. The highest total insolation per day was $25 \mathrm{MJ} / \mathrm{m}^{2}$, which was a day with heavy cooling load. Cooling was done to the set temperature (variable) only in the time zone in which the user was located. Therefore, unlike the aforementioned winter seasons, the room temperature variation range $\left(25-29^{\circ} \mathrm{C}\right)$ was relatively large. Fig. 8 shows the instantaneous power and system COP of the GHP.

The operation of the heat pump is mainly carried out in the daytime, when the outside air temperature is high, and is intermittently performed throughout the night. The mode of operation was similar to that of the winter season. The heat pump has a one-time operation time of about 7 minutes and a total operation time of 147 minutes per day. The average instantaneous power was about $2.6 \mathrm{~kW}(\sigma=0.06)$ and the average system COP was 4.4 $(\sigma=0.30)$. Fig. 9 shows the return and supply temperatures of the cold water supplied by the heat pump.

The average cold-water supply and return temperatures were $11.9^{\circ} \mathrm{C}$ and $16.3^{\circ} \mathrm{C}$, respectively, which are about $5^{\circ} \mathrm{C}$ higher than those of the general cooling system, which are $7^{\circ} \mathrm{C}$ and $12^{\circ} \mathrm{C}$, respectively. This operating characteristic is the reason why the COP of the GHP increased. 


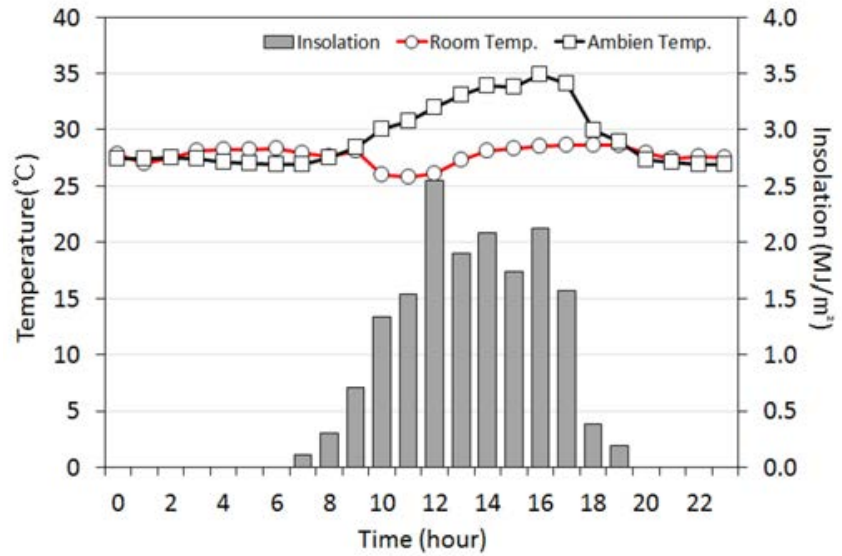

Figure 7: Room and ambient temperatures.

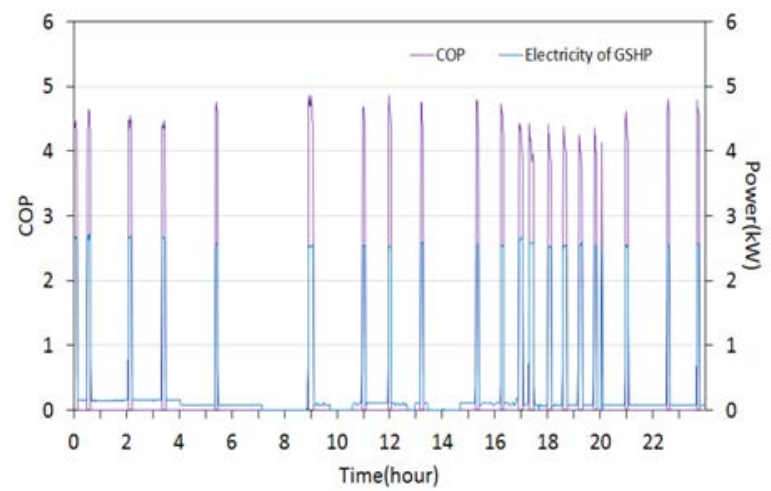

Figure 8: COP and electrical input power of GSHP.

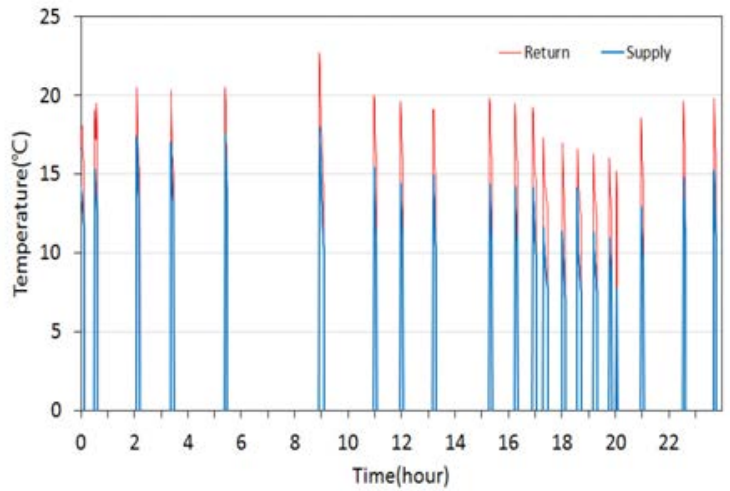

Figure 9: Cold water supply and return temperatures of the house. 


\subsection{Annual heating and cooling performance}

Fig. 10 shows the daily average supply and return temperatures of the heating medium circulated to the borehole heat exchanger during the heating period (from November to February). It can be seen that the outlet temperature of the borehole heat exchanger gradually decreases from $13^{\circ} \mathrm{C}$ at the beginning of the heating period (early November) to $9^{\circ} \mathrm{C}$ at the end of the heating period (end of February). This is due to the gradual decrease in the temperature around the borehole heat exchanger. The average temperature difference between the supply and return during this period is $2.3^{\circ} \mathrm{C}$, which is lower by $4-5^{\circ} \mathrm{C}$ than that of the general system in Korea. Note that the daily supply and return temperatures vary because the temperatures around the borehole and of the buffer tank vary depending on the daily operation time. The longer the operating time of the GHP, the lower the temperature around the borehole, which results in a decrease in the temperature difference between the supply and return.

Fig. 11 shows the correlation between the heating COP of the GHP and the average temperature of the heat medium supplied from the borehole heat exchanger to the heat pump. This shows that the higher the temperature of the heating medium, the higher the COP, with the variation range of COP during the winter season being 3.7-4.6. The results show the importance of ground temperature and the capacity and performance of the borehole heat exchanger. In this system, COP increased by 0.146 for every $1^{\circ} \mathrm{C}$ increase in the ground temperature.

Fig. 12 shows the daily average supply and return temperatures of the heat medium circulated to the borehole heat exchanger during the cooling period (June to August). The temperature variation of the heating medium at the outlet of the underground heat exchanger is $14-17^{\circ} \mathrm{C}$, which is relatively small compared to the heating period. This is due to the light cooling load and more intermittent load patterns.

Fig. 13 shows the correlation between the cooling COP of the GHP and the average temperature of the heat medium supplied from the borehole heat exchanger to the heat pump. The figure shows that as the temperature of the heating medium increases, the system COP decreases, with the variation range of COP being 3.9-4.7. Furthermore, as the temperature of the heating medium increases, the system COP decreases, with the variation range of COP being 3.9-4.7.

Table 3 compares the annual cooling and heating performances of GHP. From these results, it was analyzed that the amount of heat energy supplied is 7.5 times or more than that of cooling. The amount of heat energy supplied may vary depending on various factors, such as the lifestyle of the resident, residence time, and number of residents. Unlike office buildings, residential buildings are not always air-conditioned, and therefore, there may be a significant difference depending on the occupancy conditions (e.g. residence time, number of residents) of the resident(s).

The average cooling and heating system COPs per year was 4.2 and 4.1, respectively. This is considered to be attributable to the lowering of the heat storage temperature and the heating water supply temperature of the heating buffer tank and the increase in capacity for the underground heat exchanger for efficient system operations as described above. 


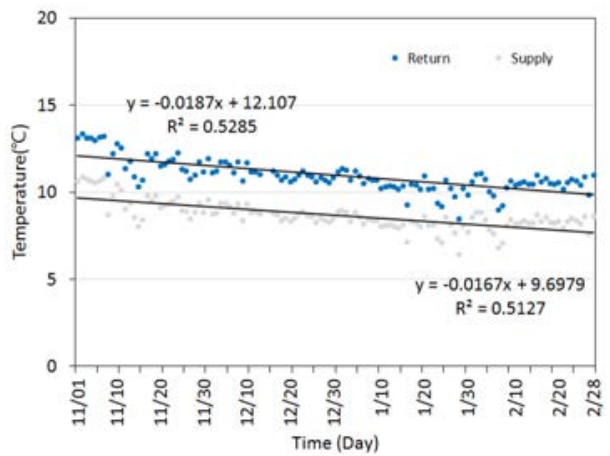

Figure 10: Daily average supply and return temperatures of the ground loop during the winter period.

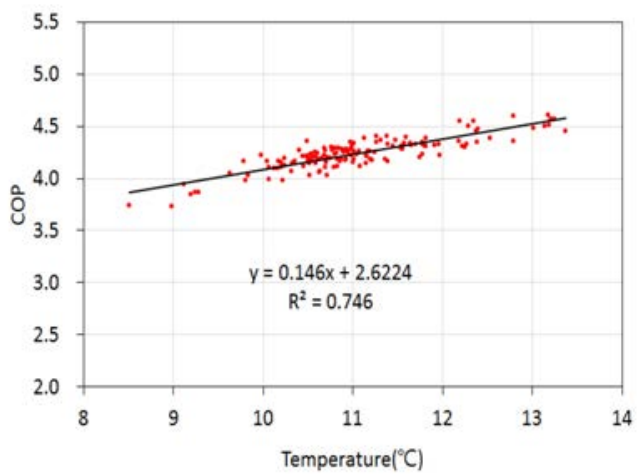

Figure 11: Heating COP with the return temperature of the ground loop during the winter period.

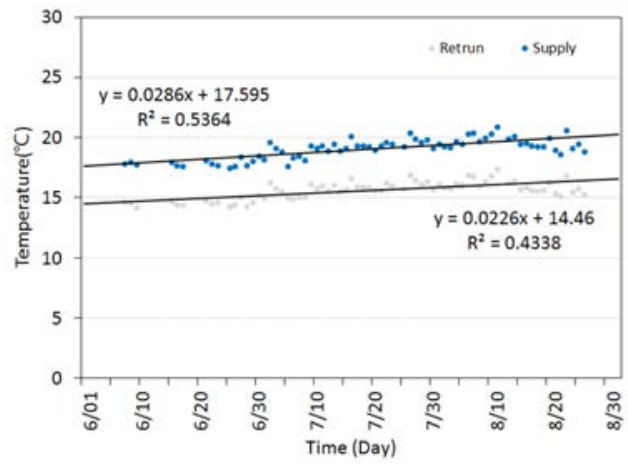

Figure 12: Daily average supply and return temperatures of the ground loop during the summer period. 


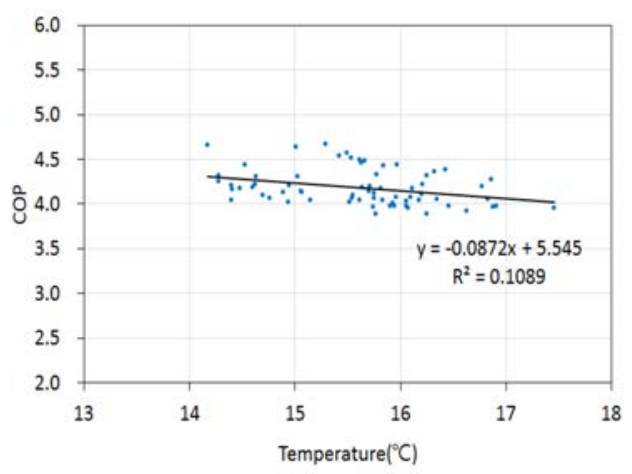

Figure 13: Cooling COP with the return temperature from the ground loop during the summer period.

Table 3: Seasonal COP of the GHP.

\begin{tabular}{|l|l|l|l|}
\hline & $\begin{array}{l}\text { Thermal output } \\
(\mathrm{kWh})\end{array}$ & $\begin{array}{l}\text { Electricity } \\
(\mathrm{kWh})\end{array}$ & Remarks \\
\hline Heating & 7,702 & 1,815 & 4.2 \\
\hline Cooling & 1,062 & 259 & 4.1 \\
\hline
\end{tabular}

\section{CONCLUSIONS}

In this study, the operating characteristics and performance of the GHP for a solar thermal and geothermal hybrid system developed for the heating and cooling of a zero-energy house were experimentally analyzed. This hybrid system was designed and built to be compact based on preceding studies. The house for which this hybrid system is implemented is a newly built zero-energy house with a heating area of $194 \mathrm{~m}^{2}$. The results of the experimental analysis are summarized as follows:

1. The average daily COPs of the GHP were 3.7-4.6 and 3.9-4.7 for heating and cooling, respectively. The duration and the total daily operation time of the heat pump were about 10 minutes and 271 minutes for heating and 7 minutes and 147 minutes for cooling, respectively.

2. The typical operating pattern of the GHP during the winter shows continuous intermittent operations with frequent ON-OFF operations from the evening to early morning times. To improve this abnormal operating pattern, analysis shows that either the capacity of the heating buffer tank needs to be increased or the heat pump capacity needs to be somewhat reduced. In order to make this device more compact, an output variable heat pump that can be supplied directly from the heat pump to meet the instant load size is required.

3. The temperature of the heating medium at the outlet of the borehole heat exchanger during the winter season gradually decreased from about $13^{\circ} \mathrm{C}$ in the early stages of heating to about $9^{\circ} \mathrm{C}$ towards the end of heating. This is due to the decrease in the ground temperature around the borehole heat exchanger.

4. The temperature of the heating medium at the outlet of the borehole heat exchanger during the summer season gradually increased from about $14^{\circ} \mathrm{C}$ in the early stages 
of the cooling to $17^{\circ} \mathrm{C}$ towards the end of the cooling, which is relatively lower than that during the heating period.

5. The annual power consumption of the heat pump is $1,815 \mathrm{kWh}$ for heating and hot water, and $259 \mathrm{kWh}$ for cooling. Analysis showed that the heating and hot water supply was about 7.5 times greater than that for cooling. The average annual cooling and heating COPs were 4.2 and 4.1, respectively.

\section{ACKNOWLEDGEMENT}

This research is conducted with research fund support by Korea Institute of Energy Technology Evaluation and Planning (Project Number: 20173010140800).

[1] http://greenhome.kemco.or.kr/index.do

\section{REFERENCES}

[2] Safa, A.A., Fung, A.S. \& Kumar, R., Heating and cooling performance characterisation of ground source heat pump system by testing and TRNSYS simulation, Renewable Energy, 83, pp. 565-575, 2015.

[3] Kharseha, M., Al-Khawajaa, M. \& Suleimanb, M.T., Potential of ground source heat pump systems in cooling-dominated environments: Residential buildings, Geothermics, 57, pp. 104-110, 2015.

[4] Liu, S., Shukla, A. \& Zhang, Y., Investigations on the integration and acceptability of GSHP in the UK dwellings, Building and Environment, 82, pp. 442-449, 2014.

[5] Baek, N.C., Jeong, S.Y., Yoon, E.S. \& Lee, K.O., The Development and Performance Analysis of Compact Type Solar Thermal/Ground Coupled Heat Pump Hybrid System for Heating, Cooling and Hot water, Journal of the Korean Solar Energy Society, 32(5), pp. 59-67, 2012. 